\title{
Regulación jurídica de la violencia psicológica y su incidencia en el derecho a la integridad personal en el ordenamiento jurídico ecuatoriano $^{1^{*}}$
}

\section{Legal regulation of psychological violence and its impact on the right to personal integrity in the Ecuadorian legal system}

\author{
Grisel Galiano Maritan \\ Máster en Derecho Civil \\ Universidad de Guayaquil, Ecuador \\ Directora del Proyecto de Investigación titulado "Tratamiento jurídico \\ de la violencia contra la mujer en Ecuador" \\ Correo electrónico: griselgaliano1986@gmail.com
}

\section{Resumen}

La presente investigación tiene como principal objetivo valorar la efectividad de la regulación jurídica de la violencia psicológica, frente al derecho de la integridad personal en el ordenamiento jurídico ecuatoriano. Para ello se utilizaron métodos de investigación el históricológico; exegético- analítico, y el jurídico comparado, y la técnica de investigación de análisis de documentos. El trabajo se ha desarrollado teniendo en cuenta el tratamiento doctrinal, legal

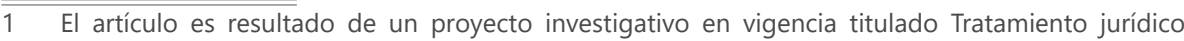
de la violencia contra la mujer en Ecuador, dirigido por la autora, Msc. Grisel Galiano Maritan, desarrollado en la Facultad de Jurisprudencia y Ciencias Sociales y Políticas de la Universidad de Guayaquil, Ecuador. 
y jurisprudencial que se le brinda a la interrelación existente entre la violencia psicológica y el derecho a la integridad personal. Para ello, se estudia el concepto violencia psicológica, determinando su alcance y principales formas de expresión; además de analizar el derecho a la integridad personal como derecho humano con protección internacional y constitucional; la interrelación que existe entre ambas figuras jurídicas, y su materialización en el contexto jurídico ecuatoriano, a partir de su tipificación dentro del Código Orgánico Integral Penal. Finalmente, como resultado, se fundamentará la necesidad de lograr una protección integral de los sectores más vulnerables de la sociedad que sufren violencia psicológica, así como la defensa del derecho a la integridad, no solo desde una perspectiva familiar, sino también social.

\section{Palabras clave}

Violencia psicológica; integridad personal; víctimas; delito; familiar.

\section{Abstract}

The main objective of this research is to assess the effectiveness of the legal regulation of psychological violence. We compare the right to personal integrity in the Ecuadorian legal system. For this, we use the historical-logical, exegetical-analytical, and comparative legal scientific research methods and the document analysis research technique. The work carries out the doctrinal legal and jurisprudential treatment to evidence the interrelation between psychological violence and the right to personal integrity. We study the concept of psychological violence to determine its scope and forms of expression. Besides, we analyze the right to personal integrity as a human right with international and constitutional protection. And, the interrelation that exists between both legal figures, and their materialization in the Ecuadorian legal context, ase don its classification within the Comprehensive Organic Criminal Code. Finally, as a result, the need to achieve comprehensive protection of the most vulnerable sectors of society that suffer psychological violence will be based, as well as the defense of the right to integrity, not only from a family perspective but also from a social perspective.

\section{Keywords}

Psychological violence; personal integrity; victims; crime; family.

Cómo citar este artículo:

Galiano Maritan, G. (2021). Regulación jurídica de la violencia psicológica y su incidencia en el derecho a la integridad personal en el ordenamiento jurídico ecuatoriano. Revista de la Facultad de Derecho y Ciencias Políticas, 51 (134), pp. 25 - 51.

doi: https://doi.org/10.18566/rfdcp.v51n134.a02

Recibido: 03 de marzo de 2020

Aprobado: 07 de octubre de 2020 


\section{A modo de introducción}

La Constitución de la República del Ecuador reconoce, de forma expresa, la protección del derecho a la integridad personal, y dentro de este la integridad física, psíquica, moral y sexual (cfr. Constitución Política de Ecuador, Artículo 66). Al propio tiempo, reconoce con carácter especial la protección de este derecho en sectores vulnerables como los adultos mayores (cfr. Constitución Política de Ecuador, Artículo 38.4), las niñas, niños y adolescentes (cfr. Constitución Política de Ecuador, artículos 45 y 46.4) y las personas con discapacidad (cfr. Constitución Política de Ecuador, Artículo 48.7), personas que, al encontrarse en condiciones de vulnerabilidad, son sujetos de atención prioritaria, dentro de las cuales se encuentran las víctimas de violencia (cfr. Constitución Política de Ecuador, Artículo 35).

La protección conferida para estos sectores vulnerables ha conllevado el desarrollo y la modificación de múltiples legislaciones complementarias como la Ley contra la Violencia a la Mujer y la Familia (1995); el Código de la Niñez y la Adolescencia ( 2003), así como el Código Orgánico Integral Penal, en adelante COIP ( 2014); de igual forma, se cuenta con la aprobación de la reciente Ley Orgánica para Prevenir y Erradicar la Violencia contra las Mujeres ( 2018).

Sin embargo, pese a las garantías legales que se establecen, aún es evidente la incidencia del fenómeno de la violencia psicológica dentro de la sociedad ecuatoriana. Por otro lado, sobresale la laceración de la que es objeto el estudio de este fenómeno, al excluirse del tratamiento su expresión en otros grupos vulnerables que no son exclusivamente las mujeres.

Tampoco existe uniformidad en la utilización del concepto violencia intrafamiliar o el de violencia de género contra las mujeres (Laurenzo Copello, 2005, p. 2). En este sentido, siguiendo a Camacho, la expresión violencia de género contra las mujeres es el criterio que debe seguirse, teniendo en cuenta que es más amplio cuando se distinguen y visualizan las causas de agresión contra las mujeres (Camacho, 2014, p. 21). Sin embargo, si bien ello pudiera ser así, lo cierto es que se debe considerar que la violencia contra las mujeres no es la única expresión del fenómeno de la violencia psicológica, pues con su estudio y tratamiento se obvian otros sujetos vulnerables, como son los menores de edad y los discapacitados (Sempere Faus, 2019, p. 63).

A pesar de que los estudios estadísticos sobre la violencia psicológica se realizan de forma determinante desde la perspectiva de la violencia de género, 
se puede corroborar, de acuerdo con los informes del Instituto Nacional de Estadísticas y Censos (en adelante INEC), la ausencia de datos que reconozcan la incidencia de este fenómeno en otros sectores. No obstante, aun cuando el Estado ecuatoriano se preocupa por el desarrollo y aplicación de políticas públicas para contrarrestarlo, la temática sigue siendo una preocupación que continúa sin resolverse (Mora Mojena, 2019, pp. 65-79).

Por solo mencionar algunos ejemplos, en el año 2015, en el Ecuador se produjeron más de 16000 casos de violencia psicológica (El Universo, 2015), información confirmada con los datos ofrecidos en la primera encuesta de relaciones familiares y violencia de género realizada en el país durante el año 2011. Los datos ofrecidos por esta encuesta corroboraron que 6 de cada 10 mujeres mayores de 15 años sufrieron algún tipo de violencia de género; siendo la más frecuente la psicológica o emocional $(53,9 \%)$, a diferencia de la física (38 \%), la sexual $(25,7 \%)$ y la patrimonial $(16,7 \%)$.

En este sentido, según el Observatorio de Violencia de Género del Consejo de Seguridad Ciudadana, en el cantón de Cuenca, se presentaron en ese propio año 3704 denuncias en la Unidad Judicial Especializada en Violencia, de las cuales 1058 fueron por concepto de violencia psicológica, tipificándose así como principales tipos delictivos el abuso sexual (61), el acoso sexual (25), la violación al pudor (86), la violencia intrafamiliar (54), el atentado al pudor (JBS, 2016), (Consejo de Seguridad, 2019), entre otros.

En correspondencia con lo expuesto, puede afirmarse que la violencia psicológica se encuentra entre los tres delitos más denunciados en Ecuador según informe de las fiscalías provinciales, como parte de los reportes realizados en el año 2016. En Guayas y Galápagos la violencia psicológica ocupa el segundo lugar de las estadísticas, con 13574 casos reportados. En Loja, la violencia psicológica ocupa el primer lugar de los delitos registrados, con 1321. La rendición de cuentas proporcionada en Azuay reporta que, solamente en Cuenca, se denunciaron 2372 casos. La realidad de Chimborazo no es diferente, pues en 6 de los 10 cantones, la violencia psicológica fue la infracción más denunciada. En la provincia de El Oro hubo 3458 eventos, situación similar a la reportada en Manabí, donde se documentaron 4583 hechos. En Bolívar, Cotopaxi, Napo y Pastaza, este delito se situó en el tercer lugar y la provincia de Santa Elena en el cuarto, superado únicamente por los robos, los hurtos y la intimidación ${ }^{2}$. En el año 2019 se registraron 2188

\footnotetext{
2 Vid. Noticia publicada originalmente por Diario EL TELÉGRAFO. Disponible en: https://www. eltelegrafo.com.ec/noticias/39/13/13-574-casos-de-violencia-psicologica-en-guayas
} 
reportes de caso, y actualmente, según fuentes oficiales, durante la pandemia que ha azotado al mundo, y en especial a Ecuador, las denuncias por violencia psicológica aumentaron en un 80 \%. Antes se contabilizaba un promedio de 25 denuncias semanales, y ahora son alrededor de 40, precisamente porque, como afirmó Barriga Carranza, jefe del Departamento de Violencia Intrafamiliar (Devif) de la Policía Nacional Tungurahua, en este tiempo la convivencia diaria es un motivo de estrés y las personas reaccionan de diferentes formas, donde las agresiones psicológicas toman gran fuerza (La Hora, 18 de mayo de 2020).

El Derecho, y en especial el Derecho Penal, constituyen una valiosa herramienta en el castigo y enfrentamiento al agresor, sin embargo, aún quedan múltiples escenarios de violencia psicológica que se escapan del ámbito legal. La incidencia de la violencia psicológica en múltiples contextos, en nuestro país, responde también a condicionamientos sociales y económicas, a patrones culturales ya establecidos, conductas repetidas, y patrones institucionales que hacen que, en la gran mayoría de los casos sea difícil reconocer estas expresiones de violencia (Guarderas, 2014, p. 99).

A estos condicionamientos deben agregarse otros factores, como el hecho de que no todas las personas acuden a denunciar el delito cometido, ya sea porque no confían en el sistema judicial (29.9\%), por falta de tiempo (13.61 \%), entre otros motivos (Instituto Nacional de Estadística y Censos, 2011).

Al respecto, resulta importante estudiar no solo las condiciones que fomentan, y en virtud de las cuales nace y se desarrolla la violencia en cualquiera de sus expresiones, sino también cuáles son sus principales formas de expresión y sus efectos en los más diversos ámbitos, dentro de los cuales no puede escapar el jurídico, el cual se torna en un poderoso instrumento para contrarrestar cualquiera de las condicionantes de las diversas formas de expresión de la violencia.

Por lo general, la incidencia del derecho en este fenómeno se analiza desde la perspectiva del derecho penal, lo cual es recurrente; sin embargo, no se puede obviar que, si bien el ordenamiento punitivo constituye un elemento esencial en la lucha de las sociedades para eliminar cualquier expresión de violencia, no es esta la única perspectiva. La complejidad del fenómeno hace que sea necesario analizarlo desde un enfoque integral y multidisciplinar, tanto desde lo social, como desde el propio derecho. Por ende, además de la mirada penal, el fenómeno necesita ser analizado desde otros contextos, como pueden ser el constitucional, familiar, entre otros. 
En correspondencia, se plantea como objetivo fundamental de esta investigación valorar la efectividad de la regulación jurídica de la violencia psicológica, frente al derecho de la integridad personal en el ordenamiento jurídico ecuatoriano, teniendo en cuenta la relación que se establece entre el ejercicio de la violencia psicológica, y la vulneración de la integridad personal como derecho constitucional.

\section{Violencia psicológica. Definición}

La violencia es un fenómeno que ha golpeado a la humanidad desde el principio de su historia y hasta la actualidad, y se manifiesta de diversas formas. Se trata de un comportamiento que trae consigo consecuencias nefastas, no solo para quien lo sufre directamente, mujeres, hombres, ancianos, niños; sino también para la familia y la sociedad en general. Por ello se ha convertido es una temática de primer orden (Perela Larrosa, 2010, p. 354).

Cuando se estudia la violencia en general, nos percatamos de que uno de los principales problemas es la ausencia de una definición que abarque las diversas formas en las que esta puede presentarse, por ello, resulta difícil ofrecer una conceptualización que pueda considerarse abarcadora y única, pues se trata de una expresión que se desarrolla desde diversos enfoques, y precisamente, la presente investigación se acerca a uno de ellos: el enfoque psicológico.

No obstante, antes de adentrarnos en el estudio de la violencia psicológica específicamente, se analizará brevemente lo que se entiende por el término violencia, traducción del vocablo latino "violentia”, derivado de la raíz “violo”, que quiere decir atentar o violar (Cabanellas de Torre, 1993).

Etimológicamente, la palabra violencia significa fuerza, y se utiliza para producir un daño a otra persona. Dentro de ella pueden identificarse la violencia política, económica, social, entre otras, las cuales se relacionan estrechamente al concepto de poder (Guevara, 2007, pág. 31 y 32) (Vivanco Martínez, 2011, pp. 215 y 216).

La Organización Mundial de la Salud (OMS) define la violencia como "el uso deliberado de la fuerza física o el poder, ya sea en grado de amenaza o efectivo, contra uno mismo, contra otra persona, o contra un grupo o comunidad, que ocasione o tenga varias probabilidades de causar lesiones, muerte, daño psicológico, trastorno del desarrollo o privaciones” (Organización Mundial de la Salud, 2002, p. 4). 


\section{Informe mundial sobre la violencia y la salud}

Para el Diccionario de la Real Academia de la Lengua Española (RAE), el término psicológico se remite a aquello que pertenece 0 es relativo a la psique, mientras que este último término, que proviene del griego psychế, que significa, en su única acepción, alma, principio de la vida (Real Academia de la Lengua Española, 2014). Sin embargo, con la opinión de García Calderón, no podemos circunscribir este concepto única y exclusivamente a la mente, sino también a la enfermedad de la mente, es decir, no podemos olvidar que los términos psicológicos y psíquicos son términos sucesivos. El maltrato puede provocar daño psicológico o moral, o ir más allá y ocasionar una enfermedad mental que requiera tratamiento médico (García Calderón, 2000, p. 207).

De allí que se entienda por violencia psicológica aquella agresión recibida por una persona, sin que medie contacto físico entre ellas, con el objetivo de desmerecer a la otra. Justamente, por esa razón, es difícil de probar, pues su marco de realización es ambiguo y subjetivo (Cáceres Carrasco, 2004, pp. 3542), (Torrico Linares, 2011, pp. 32-40).

El ordenamiento jurídico ecuatoriano, recientemente, mediante la Ley Orgánica Integral para Prevenir y Erradicar la Violencia contra las mujeres, ha definido acertadamente, en su Artículo 10, inciso b), la violencia psicológica como:

“Cualquier acción, omisión o patrón de conducta dirigido a causar daño emocional, disminuir la autoestima, afectar la honra, provocar descrédito, menospreciar la dignidad personal, perturbar, degradar la identidad cultural, expresiones de identidad juvenil o controlar la conducta, el comportamiento, las creencias o las decisiones de una mujer, mediante la humillación, intimidación, encierros, aislamiento, tratamientos forzados o cualquier otro acto que afecte su estabilidad psicológica y emocional. La violencia psicológica incluye la manipulación emocional, el control mediante mecanismos de vigilancia, el acoso u hostigamiento, toda conducta abusiva y especialmente los comportamientos, palabras, actos, gestos, escritos o mensajes electrónicos dirigidos a perseguir, intimidar, chantajear y vigilar a la mujer, independientemente de su edad o condición y que pueda afectar su estabilidad emocional, dignidad, prestigio, integridad física o psíquica; o, que puedan tener repercusiones negativas respecto de su empleo, en la continuación de estudios escolares o universitarios, en promoción, reconocimiento en el lugar de trabajo o fuera de él. Incluye también las amenazas, el anuncio verbal o con actos, que deriven en un daño físico, 
psicológico, sexual, laboral o patrimonial, con el fin de intimidar al sujeto de protección de esta Ley” (2018, p. 9).

Son múltiples y variadas las formas de expresión de la violencia psicológica, desde la ridiculización, gritos, descalificaciones e insultos realizados de forma íntima y pública, hasta vejaciones, amenazas, faltas de respeto, así como asignación de culpa a la víctima (Vilariño, 2011, pp. 94-100). Los efectos que pueden derivarse de ella son diversos, tales como los miedos, las angustias, depresiones, frustraciones, afectación de la facultad de autodeterminación, el orgullo, la confianza, y también el respeto pudiera incluirse entre estos (GarcíaBaamonde Sánchez, Blázquez Alonso, \& Moreno Manso , 2012, p. 628).

Cada una de estas formas de expresión de la violencia desempeña disímiles efectos en cada una de las víctimas, por ejemplo, el aislamiento es comúnmente utilizado en el caso de los menores de edad (Bueno Bueno, 1997, p. 87), al igual que la suspensión o privación de la víctima de dinero, como sucede comúnmente en las relaciones de pareja. Y es que, tanto en uno como en otro supuesto, no solo se afianza el poder económico de quien ejerce la violencia, sino también se corrobora una actitud de dominio de la cual se desprenden disímiles consecuencias, entre las que sobresalen, la privación de múltiples necesidades, incluidas aquellas que pudieran ser consideradas vitales o necesarias para el desarrollo integral de la personalidad.

Estas expresiones de violencia también pudieran estar relacionadas con cambios y modificaciones en las propias concepciones ideológicas y políticas de la víctima, que pudiera ver expuesta su libertad de elección política a los propios designios de quien ejerce el poder económico, incidiendo cada una de ellas en la autoestima de la víctima.

Sin embargo, es imposible establecer una relación directa entre la persona que comete el acto violento, y el sujeto que la sufre (Antón García, 2014, p. 69). En esta relación, desempeña un papel esencial el individuo, por ello, a los efectos de tener en cuenta las circunstancias en las que ocurre el acto violento y su valoración, es necesario analizar la situación personal del agresor y, por supuesto de la víctima, para determinar la trascendencia en el ordenamiento jurídico del Ecuador.

Debe, además, tenerse en cuenta que la violencia psicológica se comienza a manifestar desde actos tan sencillos como el aislamiento familiar y social, así como la manipulación de la autoderminación de la víctima. Estos actos, que 
son expresiones generalizadas de la violencia psicológica, se suelen confundir con otros sentimientos, y, en la gran mayoría de las veces, la víctima puede llegar a considerar que estas son expresiones de cariño, amor o protección (Guarderas, 2014, p. 85).

En conclusión, la violencia psicológica es aquella ejercida mediante concuctas y agresiones que no son precisamente físicas, pero, que, sin embargo, dañan la autoestima de la persona, estableciendo una relación de poder sobre ella. Por esas razones, se considera una de las más comunes en todos los ámbitos, $\mathrm{y}$, por ende, puede identificarse por conductas como el acoso, la manipulación, o el maltrato, que degradan constantemente a la víctima. En esta clase de violencia se identifican esencialmente el maltrato verbal, las actitudes controladoras, la difamación ante terceros, la separación de la persona de su círculo de protección, e incluso, amenazas de toda índole.

\section{Ámbitos de la violencia psicológica}

Es muy común que se relacione la violencia psicológica solo al ámbito intrafamiliar. De hecho, en la búsqueda bibliográfica para la realización de este artículo, se observó que este tema solo se analiza desde esta perspectiva o desde o desde el tema de la igualdad de género. Sin embargo, esto significa un errado tratamiento del asunto, puesto que la violencia psicológica no es una temática privativa de lo que sucede en cada hogar en relación con la igualdad de género, sino que, por el contrario, tiene una manifestación también desde el ámbito social e institucional (Zurita Rivera, 2011, p. 145).

Por lo general, la tipificación de la violencia psicológica se realiza desde la perspectiva de la violencia de género; sin embargo, si bien aquella es una de las principales manifestaciones de esta última, no abarca necesariamente todos los supuestos de esta, es decir, puede- y de hecho existe violencia psicológica en la violencia de género-, empero, es necesario reconocer que existen casos de violencia psicológica que no quedan contemplados dentro de la violencia de género.

Es necesario recordar que la violencia de género presenta características que la convierten en peculiar, que este flagelo tiene características incluso desde su tipificación en el derecho penal. Pudiera decirse que solo nos encontramos en presencia de violencia de género cuando esta es ejercida por el hombre sobre la mujer, cuya causa se manifiesta en una situación de desigualdad motivada por las relaciones de poder de los hombres sobre las mujeres, en un contexto 
en el cual existe o ha existido una relación de afectividad, específicamente de pareja o similar (Ramón Ribas, 2013, p. 406).

Evidentemente, esta delimitación excluye una serie de supuestos de violencia psicológica que quedan olvidados dentro del estrecho y limitado marco de la violencia de género. Si bien pudiera argumentarse que la delimitación que se hace de este último tipo de violencia se sustenta precisamente en el fin perseguido por este tipo de norma, generalmente se intenta subvertir cualquier manifestación de discriminación del género, limitando sobradamente el tipo penal. De allí que, en ocasiones, sea necesario tener que acudir a otros tipos penales dentro de los cuales se tipifica o protege el bien jurídico de la integridad personal, como pueden ser los delitos de amenaza, lesiones, coacciones, entre otros.

De esta forma se excluye el tratamiento, al menos desde el derecho penal, del sufrimiento invisible de los individuos más vulnerables de la sociedad, tal como catalogara Nelson Mandela a este fenómeno al prologar el primer Informe Mundial sobre la violencia y la salud, elaborado por la Organización Mundial de la Salud (2002, p. 3). Se refería así el Premio Nobel de la Paz a la violencia psicológica que era ejercida sobre la pareja, los hijos y demás descendientes, los padres o demás ascendientes y discapacitados, empleados, y otros sectores vulnerables.

La laceración de la autoestima de la persona, el menoscabo de su concepción personal ante sí mismo y ante la sociedad, significa la vulneración de múltiples bienes jurídicos merecedores de tutela jurídica, como la libertad del individuo, el libre desarrollo de la personalidad, la integridad física y moral, así como la protección de la familia, e incluso, la protección integral de los menores de edad, y, en sentido general, la dignidad personal vista como el valor supremo y el principio a partir del cual se fundamentan el resto de los derechos humanos.

\section{El derecho de integridad personal. Su concepción como derecho humano}

Es claro que el derecho de integridad personal es un derecho humano, el cual deviene fundamental no solo desde la teoría de los derechos fundamentales como un derecho positivamente válido (Alexy, 1993, p. 28), sino también por su inherencia con la dignidad humana. El bien jurídico protegido en este derecho abarca cualquiera de las tres dimensiones de la persona: el ser físico, el ser 
psíquico y el ser social, los cuales conforman los presupuestos de los derechos humanos (Russo, 2001, p. 43).

Como acertadamente señala Afanador, son tres las aristas del derecho a la integridad personal: el físico, psíquico y el moral (2002, p. 93). El primero se relaciona con la plenitud corporal del individuo, mientras que el segundo y el tercero tienen que ver con las facultades morales, intelectuales y emocionales. En el caso de la arista física, esta tiene como objeto de protección el cuerpo del individuo, mientras que la psíquica y la moral se vinculan con la mente y su voluntad. Estos casos, al decir de Huertas Díaz, cursan a partir de dos facetas, una en sentido positivo, que se configura a partir del derecho a gozar de una integridad física, psicológica y moral; y una en sentido negativo, que establece el deber de no maltratar, ofender, torturar y no comprometer o agredir la integridad física y moral de las personas (2007, p. 158).

La infracción de este derecho se configura no solo ante la laceración o pérdida de la integridad de las personas en cualquiera de los ámbitos anteriormente expuestos, sino también ante la mera disminución o intento de supresión de alguna de las facultades que lo conforman. Se trata de un derecho que es inderogable, que bajo ninguna circunstancia puede ser suspendido ni en las circunstancias más complejas, como pueden ser la guerra, o cualquier otra circunstancia excepcional, pues este derecho pertenece al dominio del ius cogens (Fernández Torres, 2013, p. 124).

La importancia que reviste el derecho de integridad personal es tal, que ha sido reconocido, directa o indirectamente, en gran parte de tratados internacionales, entre los que pueden citarse la Declaración Universal de los Derechos Humanos (artículos. 3 y 9); el Pacto Internacional de Derechos Civiles y Políticos (artículos. 7 y 9); la Convención de las Naciones Unidas sobre la Tortura (artículos. 1 y 2); la Convención sobre los Derechos del Niño (artículo 37) y la Convención de los Derechos de las Personas con Discapacidad (artículos 4 y 15), entre otros instrumentos internacionales. En el continente americano sobresalen las disposiciones que, a tales efectos, se consagran en la Declaración americana sobre los deberes y derechos del hombre, (1948) en sus artículos 1, 25 y 26; así como en la Convención Americana sobre los Derechos Humanos, (Convención Americana sobre Derechos Humanos "Pacto de San José” , 1969), artículos 5 y 7.

En este contexto, la Convención Americana sobre los Derechos Humanos es uno de los instrumentos internacionales que, con mayor precisión, ha 
reconocido el carácter integral del concepto de integridad personal. El Artículo 5.1 de la Convención establece que "toda persona tiene derecho a que se respete su integridad física, psíquica y moral” (Convención americana sobre Derechos Humanos, 1969, p. 3).

No obstante, ha sido la Corte Interamericana de Derechos Humanos (en adelante, CIDH) la que, en virtud de una profusa jurisprudencia, ha impulsado este derecho, aplicándolo consecuentemente a cada uno de los casos concretos que le ha tocado resolver; y son precisamente estas disposiciones de carácter internacional las que sirven para ilustrar la importancia y el impacto de la integridad personal en los casos de violencia psicológica. Por citar algunos ejemplos, tenemos los siguientes: Caso Loayza Tamayo vs. Perú, (1998); Caso Villagrán Morales y otros vs. Guatemala, (1999); Caso Ximenes Lopes vs. Brasil, (2007); Caso Masacre de Santo Domingo vs. Colombia, (2012).

De manera brillante, este órgano jurisdiccional se ha encargado de establecer los límites de este derecho, no solo cuando su vulneración tiene como origen un acto de violencia cometido por los propios particulares, sino también cuando la fuente del mismo es el Estado, en la persona de sus agentes y funcionarios.

Tanto en uno como en otro caso, la obligación del Estado para garantizar la efectividad de este derecho en su jurisdicción reside en la implementación de acciones de prevención y medidas operativas eficaces que protejan a todas las personas, especialmente, aquellas que más posibilidades tienen de sufrir algún tipo de vulneración en su plenitud corpórea y espiritual, es decir, los sectores más vulnerables de la sociedad (García-Toledano, 2018, p. 69); (Organización de Estados Americanos, 2009).

Como ha reafirmado la CIDH, la infracción de este derecho tiene diversas connotaciones de grado, cuyas secuelas físicas y psíquicas “varían de intensidad según los factores endógenos y exógenos que deberán ser demostrados en cada situación concreta” (Caso Loayza Tamayo vs. Perú, 1998, pp. 4-59). Los primeros de estos factores se refieren a las características del trato, tales como la duración, el método utilizado, o el modo en que fueron infligidos los padecimientos, así como los efectos físicos y mentales que causan; mientras que los segundos, remiten a las condiciones de la persona que padece dichos sufrimientos, entre los cuales encontramos la edad, el sexo, el estado de salud, así como cualquier otra circunstancia personal. 
Sin embargo, no siempre han quedado bien precisados los límites de este derecho, sobre todo en su relación con otros, como son el derecho a la salud y el derecho a la vida. Es innegable que estos derechos mantienen una estrecha e ineludible relación, que hace, en muchos casos difícil la práctica de su contenido, pues parten o tienen como esencia o fundamento la propia vida humana, y, en consecuencia, el derecho a la vida. Dada la relación existente entre estos derechos, algunos autores, como Pérez Royo, afirman que en el ordenamiento jurídico español, el derecho a la vida incluye el derecho a la integridad física y moral (Pérez, 1995, p. 290).

La interpretación realizada por el constitucionalista español es consustancial con la propia regulación, que sobre este precepto realiza la Constitución española, que en su Artículo 15 reconoce tanto el derecho a la vida, como el derecho a la integridad física y moral. Sin embargo, a nuestro juicio, y respetando el criterio del citado autor, parece más atinado concebir la independencia de ambos derechos, posición que también comparte Canosa Usera (2006, p. 99).

A nuestro entender, desde el punto de vista doctrinal, resulta factible realizar tal distinción. A estos efectos, órganos como la Corte Constitucional de Colombia en sentencia N. ${ }^{\circ} \mathrm{T}-23 / 94$, del 14 de marzo de 1994, ha reconocido que la diferencia de estos derechos se encuentra precisamente en "el objeto jurídico protegido de manera inmediata”. Para la Corte Constitucional colombiana, el derecho a la vida no es más que el acto de vivir en sí mismo considerado; mientras que la integridad física y moral no es más que la plenitud y totalidad de la armonía corporal y espiritual del hombre. En el caso del derecho a la salud, este reside en el normal funcionamiento orgánico del cuerpo y el adecuado ejercicio de las facultades intelectuales.

En el caso ecuatoriano, la Constitución instituye explícitamente los derechos de la personalidad, entre los que se encuentra el derecho a la vida (artículo 66.1 y 66.2). En él se expresa que se garantiza y reconoce a las personas el derecho a la inviolabilidad de la vida, y no habrá pena de muerte; por lo que no cabe duda alguna que su reconocimiento constitucional forma a su vez, la propia garantía que asegurará su ejercicio (Galiano Maritan, 2016, pág. 75 y 76).

La Corte Nacional de Justicia, en su Sala Penal, mediante la Sentencia N. ${ }^{\circ}$ 29-02-2012 de fecha 29 de febrero de 2012 declara que: "El derecho a la vida constituye uno de los derechos básicos del hombre, reconocido por los ordenamientos jurídicos a nivel internacional, no siendo la excepción el 
ordenamiento ecuatoriano, que reconoce al derecho a la vida como un derecho esencial de la persona y en tal sentido es objeto de protección jurídica; por tanto, quien atenta contra la vida de otro ser humano, comete un acto, que al constar en el canon de delitos, es típico, y, es innegable que este rompe la ley del Estado, por lo que deviene en antijurídico, si no hay causas de justificación, como en la especie, por lo que, su consecuencia lógica, constituye el juicio de reproche que elabora la sociedad en contra de quien cometió la infracción, esto es, la sanción penal (...)” (Sentencia N. ํ 29-02-2012, 2012).

En tal sentido, se puede afirmar que la vida, como derecho subjetivo personalísimo, es inviolable, y con ella se protege una vida digna que asegure entre otros, el derecho a la salud (Artículo 34 de la Constitución de la Republica ecuatoriana). La concepción de este derecho denota el carácter holístico de los derechos del buen vivir, pues su ejercicio se vincula directamente al ejercicio de otros derechos. Por esa razón, el Estado se hace responsable de establecer las garantías para la realización del derecho a la salud, teniendo en cuenta los principios que estipula el propio precepto (Galiano Maritan, 2018, pp. 147 y 148).

\section{Violencia psicológica y derecho a la integridad personal}

Siendo el bien jurídico protegido por el derecho de integridad personal el de la inviolabilidad de la persona en su concepción más amplia, lo que incluye el cuerpo humano con todos sus componentes, potencialidades intelectuales y sensoriales (Canosa Usera, 2006, p. 89), se debe reconocer que la violencia psicológica constituye una práctica que vulnera la integridad moral y psicológica del individuo. Lo que sucede es que, al igual que en el caso de la determinación de la violencia psicológica, el sentido de la integridad moral tampoco es claro. Como afirma el propio autor, lo único claro es que este concepto es de ineludible tratamiento dentro del derecho de integridad personal (Canosa Usera, 2006, p. 88).

Si bien las expresiones más graves de vulneración del derecho a la integridad personal son la desaparición forzada de personas y la tortura, debemos reconocer que estas no son las únicas, pues su ámbito de protección implica todas las facetas intelectuales y emocionales del desarrollo del individuo (Anello, 2012, p. 64). En este sentido, la CIDH ha señalado que la infracción de este derecho tiene diversas connotaciones de grado, abarcando desde la tortura, hasta otro tipo de vejámenes o tratos crueles, inhumanos 
o degradantes, cuyas secuelas físicas y psíquicas varían y deberán ser demostradas en cada situación concreta (Caso Loayza Tamayo vs. Perú, 1998).

Por ende, se puede concluir que existe total coincidencia entre los diversos supuestos que configuran la violencia psicológica y la vulneración de la integridad psíquica y moral, parte indisoluble de la integridad personal de cada individuo, en tanto existe una relación de dependencia entre el desarrollo de cada ser humano en cualquier sociedad y sus habilidades motrices, emocionales e intelectuales, así como de sus propias convicciones personales, valores, y la correspondencia de estos con las convicciones morales y de orden público (Sar Suárez, 2008, pp. 212-213).

La concepción de integridad y plenitud personal guarda estrecha correspondencia con los criterios sobre cómo el individuo se percibe a sí mismo, y cómo lo ven los demás. Cuestiones psicológicas, éticas y morales permeabilizan la gravedad o no de las expresiones de violencia psicológica y su incidencia en el derecho de integridad (Joaquín Rodríguez, 2016, p. 70). Presenciamos así un fenómeno cubierto por razones de índole histórica y cultural, las cuales ni el derecho ni la sociedad pueden obviar, pero en los que, sin duda alguna, el elemento común denominador es la dignidad del ser humano.

Por todo ello, coincidimos con Galindo, cuando afirma que los tratos o penas crueles, inhumanos o degradantes, están revestidos de una mayor protección que cualquier otro tipo de abuso, bien sea este físico o mental ( 2009, p. 99).

En consecuencia, es totalmente factible concebir que, cuando las normas y tratados internacionales se refieren de forma expresa a este tipo de actos violentos, lo hacen desde la regulación de su máxima expresión, por tanto, habrá que entender, igualmente dentro de este concepto, aquellos otros actos violentos, que si bien no pueden ser denominados como crueles, inhumanos o degradantes, sí constituyen una violación de la integridad personal, es decir, lo que trasciende en la referencia normativa es, sin dudas, el bien jurídico protegido, más que la alusión al tipo de acto concreto que queda contemplado en la norma.

En esta estrecha relación entre la violencia psicológica y el derecho a la integridad personal, hay tres aspectos que la CIDH se ha encargado de determinar de manera contundente, y que permiten no solo comprender esta relación, sino también su alcance. A nuestro juicio, estos tres criterios determinantes son: 1). la sola amenza es suficiente para ser considerada violencia psicológica y, como tal, una infracción del derecho a la integridad 
personal; 2). los familiares de las víctimas pueden ver lacerado este derecho al sufrir violencia psicológica; y 3). no existe un criterio determinante a la hora de distinguir la tortura de los malos tratos, lo cual se torna más complejo cuando la primera se materializa en casos de tortura psicológica. A continuación, se explicarán brevemente cada uno de estos supuestos.

1). Es aceptado internacionalmente que la amenaza real o inminente de que ocurra una conducta que pudiera provocar graves consecuencias físicas o psicológicas a una persona bajo determinadas circunstancias, guarda por sí sola, entidad suficiente para menoscabar la integridad de la persona, ya sea menoscabando su aspecto psicológico, o llegando, incluso, a provocar una angustia de tal grado que pueda ser considerada tortura psicológica. Este criterio, visto desde la concepción de peligro que supone el acto violento, aquí ha sido explicado en múltiples sentencias de la Corte Interamericana de los Derechos Humanos, como es el caso Masacre de Santo Domingo vs. Colombia, entre otros.

2). Otro aspecto que hay que tener presente cuando analizamos este tema es que la violencia, en cualquiera de sus expresiones, no solo afecta a quien la padece de forma directa, sino también a otras personas, como la familia, que puede padecerla desde un punto de vista psicológico. Este ha sido el criterio defendido por la CIDH, para quien los familiares directos pueden sufrir violación de su derechos a la integridad psíquica y moral como consecuencia de las graves violaciones de derechos de las que han sido objeto sus familiares. En estos casos, por supuesto, nos encontramos en presencia de una presunción iuris tantum, que lleva a suponer al tribunal la frustración y angustia de la familia ante el sufrimiento de un ser querido (CIDH, c/Villagrán Morales y otros vs. Guatemala).

En el caso Loayza Tamayo vs. Perú, la CIDH se encarga de traer a colación el pronunciamiento de la Corte Europea de Derechos Humanos, realizado en 1974, en virtud del cual se consagra el criterio de que aún, ante la ausencia de lesiones, los sufrimientos en el plano físico y moral, acompañados de turbaciones psíquicas durante los interrogatorios, pueden considerarse como tratos inhumanos.

De igual forma, en el caso Bueno Alves vs. Argentina (Sentencia de 11 de mayo, 2007) la CIDH determina los elementos que a su juicio son constitutivos de la tortura, a saber: a). un acto intencional; b).que cause severos sufrimientos físicos o mentales, y c). que se cometa con determinado fin o propósito. 
Como se colige de los anteriores pronunciamientos, en esencia, ambos conceptos prácticamente coinciden; tampoco es clara su distinción en el Artículo 2 de la Convención Interamericana para Prevenir y Sancionar la Tortura, pues en este texto no se establece ninguna diferencia sustancial.

3). Por último, en este supuesto específico, la distinción no trasciende si se tiene en cuenta, desde un enfoque normativo, que ambos términos aparecen generalmente unidos o estrechamente interrelacionados. La idea esencial es concebir que, tanto uno como el otro caso, constituyen violaciones fragantes de la integridad del individuo.

\section{Violencia psicológica y derecho a la integridad personal en el ordenamiento jurídico ecuatoriano}

La violencia psicológica afecta tanto la salud psíquica o a la integridad moral (Peris Remón, 2019, p. 38). En tal sentido, como bien se apuntó al inicio de este trabajo, la Constitución de la República de Ecuador de 2008 reconoce, de manera clara y precisa, el derecho a la integridad personal en cualquiera de sus expresiones, física, psíquica y moral. Sin embargo, la sola positivización de este derecho no es suficiente para garantizar su efectiva aplicación en el ordenamiento jurídico ecuatoriano. Como derecho humano consagrado en el texto constitucional, este derecho está dotado de las máximas garantías, como son el contenido esencial, directa aplicabilidad, eficacia frente al Estado y frente a terceros, entre otras (Asensi, 1996, pp. 121-124). No obstante, la cuestión de los derechos humanos no se circunscribe a la enumeración de un catálogo de derechos humanos (Russo, 2001, p. 42), sino que también es necesario dilucidar las diversas variables y circunstancias que interfieren en el pleno ejercicio de estos derechos.

Una de las variables y circunstancias que inciden en el ejercicio de los derechos humanos, y particularmente, en el derecho de integridad personal, es el desarrollo legislativo en materia penal. Como bien lo señala Ferrajoli, los contenidos sustanciales del derecho en un ordenamiento jurídico determinado deben vincularse normativamente a los principios regulados en las constituciones, lo cual forma parte de las técnicas de garantía jurídica (Ferrajoli, 2004, p. 20). Desde esta perspectiva, el análisis de la relación violencia psicológica y derecho a la integridad personal tiene en la interrelación Constitución y derecho penal su principal expresión, aunque no la única. 
Lo descrito conlleva a la pregunta, hasta qué punto la legislación complementaria garantiza el derecho a la integridad personal, y, especialmente, si el Código Orgánico Integral Penal (en adelante COIP), ha sido consecuente con los límites materiales que el texto constitucional ha establecido en relación con este derecho. Para ello, se debe tener en cuenta que el tipo penal que prevé la protección de este derecho en el COIP trata el objeto de la regulación y las consecuencias jurídicas previstas en la norma (Guastini, 2001, p. 47).

El bien jurídico de la integridad personal está debidamente regulado en el COIP en la sección segunda, Delitos contra la integridad personal, del capítulo segundo, Delitos contra los derechos de libertad, título IV, Infracciones en particular, del Libro Primero, La Infracción penal. Delitos como la tortura (Artículo 151), lesiones (Artículo 152), abandono de persona (Artículo 153), intimidación (Artículo 154), y delitos contra la mujer o miembros del núcleo familiar (artículos 155-158), se encuentran regulados en esta sección.

Sin embargo, llama la atención que el legislador patrio solo reguló de forma expresa la violencia psicológica para el supuesto concreto de la violencia intrafamiliar, por lo cual se puede suponer que aquellos supuestos de este tipo de violencia que no queden comprendidos en este contexto, deberán ser protegidos de forma indirecta por cualquiera de los otros delitos regulados en la propia sección. Así mismo, también resulta interesante, desde el propio concepto y manifestación de este tipo de violencia, el criterio escogido por el redactor de la norma para determinar la existencia o no del delito de violencia intrafamiliar y su distinción de una contravención.

La principal disquisición en relación con la protección penal de la violencia psicológica consiste en delimitar la infracción penal del terreno íntimo, a los actos que, aun siendo reprochables ética y socialmente, no tienen relevancia penal alguna (Gutiérrez Romero, 2013, p. 2). En correspondencia, no puede olvidarse, que el bien jurídico protegido penalmente es de naturaleza individual conforme a las características que, como hemos venido apuntando, tiene la violencia psicológica (Olaizola Nogales, 2010, p. 291).

La naturaleza individual de la violencia psicológica debe interpretarse y aplicarse conforme a las disposiciones de los principios minimalistas y garantistas del derecho penal (artículos 3 y 4 del COIP). Tal vez por ello la doctrina está de acuerdo con el hecho de que la protección conferida desde el derecho penal no se sustenta única y exclusivamente en la ocurrencia de un acto de violencia 0 maltrato psicológico, sino que deben sumársele otros requerimientos o requisitos 
para su tipificación por el esta rama del derecho, como son la habitualidad o reiteración; su proyección de forma sucesiva; y los espacios de tiempo en los que acontece (Rodríguez Peregrina, 2015, p. 25); (Albertín Carbó \& Madurga, 2009, pp. 111-120) (Mendoza Calderón, 2004, pp. 130-145).

Estos criterios han sido reiterados por la jurisprudencia foránea, como es la sentencia número 927/2000 de la Sala de lo Penal del Tribunal Supremo español, en la que el Alto Foro español concibió que los insultos y amenazas de muerte son actos de violencia psíquica, por lo cual, cuando estén dotados de habitualidad, y teniendo en cuenta su proximidad cronológica, deben considerarse delitos.

En el ordenamiento jurídico ecuatoriano, la tipificación de los delitos contra la mujer o miembros del núcleo familiar, especialmente la violencia psicológica, se realiza en consonancia con lo dispuesto en la Ley contra la Violencia a la Mujer y la Familia. Ambos cuerpos legales coinciden en observar que la violencia psicológica provoca perturbación emocional y alteración psicológica. Sin embargo, el tipo penal regulado en el Artículo 157 del COIP no establece como criterio del tipo penal la habitualidad o el carácter sucesivo de la agresión, sino, todo lo contrario, sustentó este en la gradación entre los daños provocados por este tipo de violencia, y estableció así distintas penas en correspondencia con el daño causado. En consecuencia, la norma también establece como criterio de distinción entre el carácter de delito 0 contravención, la cantidad de días que la víctima queda impedida por motivo de las lesiones o incapacidad producida producto del acto violento en cualquiera de sus expresiones (Artículo 159 del COIP).

EL COIP adopta como criterio determinante del tipo penal, el daño causado por el acto violento, y no la ocurrencia de este propiamente. Esta posición no ataca el acto violento en sí mismo considerado, sino el daño ocasionado. El concepto equilibrio mental, que es muy ambiguo y de difícil concreción, está permeabilizado de un dinamismo que lo hace, en muchos casos, susceptible de disímil apreciación entre diversos individuos; aun cuando estos sujetos se encuentren sometidos al mismo grado o nivel de violencia, o convivan en similares condiciones sociales y económicas.

Este criterio ha sido reiterado en múltiples ocasiones por la CIDH, para el cual las características personales deben ser tomadas en cuenta al momento de determinar la vulneración o no de la integridad de la víctima, pues estas características pueden cambiar la percepción de la realidad del individuo, y, 
por ende, provocar el incremento del sufrimiento y sentido de humillación (CIDH, c/ Ximénez López vs. Brasil).

Por ello, es necesario que se hable más que de daño, de la expresión “violencia”, pues aquel no está siempre presente, así como tampoco es factible su apreciación en igual grado de intensidad. No se puede concebir que, siempre que exista violencia psíquica, existirán lesiones psíquicas; en todo caso, es posible que la primera exista y no así la segunda. La violencia física, al igual que la psíquica, puede provocar múltiples lesiones mentales, por ende, el daño psicológico no es privativo de este último tipo de violencia, todo lo contrario. La tipificación debería estar destinada y relacionada con cualquier acto de violencia sin importar si existe o no algún tipo de daño en la víctima, solo así se estaría, realizando una verdadera protección contra este tipo de actos. Además, la tipificación del delito teniendo en cuenta el daño ocasionado por la víctima, tampoco escapa de las dificultades que anteriormente referíamos sobre la tipificación de los delitos de violencia psicológica y, especialmente, todo lo relacionado con la materia probatoria. La prueba pericial es el mecanismo por excelencia para corroborar, tanto en un proceso civil como penal, el estado psicológico de la víctima y sus consecuencias; sin embargo, esta posibilidad se complejiza en aquellos casos en los cuales no existe una lesión psíquica, o de existir, esta no se exterioriza para los síntomas de un maltrato habitual de este carácter.

En muchos casos, son los efectos físicos, cuando existe este tipo de violencia, los que permitirán suponer la existencia de violencia psicológica, lo cual es lógico si se tienen en cuenta las condiciones en las que ha tenido lugar. Sin embargo, tal como se ha afirmado, no se puede obviar que existen múltiples condiciones que inciden sobre la violencia, como las físicas, económicas, sociales y personales.

Este tipo de maltrato puede aparecer de forma separada o vinculada a la violencia física, aunque, en ambos casos, hay que reconocer que tiene entidad propia (Perela Larosa, 2010, p. 359). No obstante, lo cierto es que, por lo general, este tipo de violencia viene aparejada con la violencia física, pero también a otros tipos de violencia, como la económica o la patrimonial, lo cual contribuye de manera sustancial a la hora de limitar el impacto de este flajelo, pues, en muchos casos se le brinda preferencia a la violencia física, sobre todo al momento de atender y reparar cuando, de hecho, la que mayor trascendencia que puede representar para la víctima es precisamente la violencia psicológica. 
Otra de las críticas que es necesario realizarle a la regulación penal para la protección del derecho a la integridad, desde la perspectiva del derecho constitucional y de técnica legislativa, es lo restringido que resulta la delimitación de la violación solo al ámbito intrafamiliar, dejando fuera otras esferas en las que esta ocurre, como son la institucional y social.

El concepto violencia intrafamiliar no puede abarcar el fenómeno de la violencia, pues este pone su nota distintiva en la procedencia del agresor, quien es miembro de la familia, sea cual sea su relación (Pérez Contreras, 1999, p. 914). Este criterio se ve consagrado en la propia regulación del precepto 155 del COIP, que establece como sujeto activo del tipo penal, el hecho de que quien ejecute el acto debe ser un miembro de la familia. Sin embargo, no se puede limitar el acto violento como expresión de poder solo al ambiente familiar, pues la violencia, en cualquier sentido, tiene también su origen en los ámbitos institucional, educacional y social.

Asimismo, la tipificación del delito por sí mismo no es suficiente, pues unido a su regulación normativa, es necesario desarrollar una serie de condicionamientos que garanticen la ejecución de la pena, así como la protección de las víctimas del delito y el restablecimiento del derecho a la integridad personal que ha sido quebrantado (artículos 77 y 78 del COIP).

En este punto, se coincide con Soberanes Fernández, para quien un sistema de protección real de los derechos humanos debe sustentarse en elementos tan básicos como la protección de las víctimas del delito, la posibilidad de que estas puedan intervenir en juicios, interponer los recursos, el resguardo de su identidad (Artículo 5.20 y 11 del COIP); así como el establecimiento de mecanismos alternativos para la solución de controversias en virtud de los cuales se busque la reparación del perjuicio ocasionado (Soberanes Fernández, 2008, p. 1203 y ss).

\section{Conclusiones}

El ordenamiento jurídico ecuatoriano protege de forma expresa, en la Constitución de 2008, el derecho a la integridad personal del individuo en cualquiera de sus ámbitos, dígase físico, moral o psíquico. Una de las principales formas para vulnerar este derecho en el actual contexto económico, político y social es la violencia psicológica, que provoca laceración en la autoestima del individuo y el menoscabo de la concepción personal que este tiene de sí mismo. 
Una de las principales formas de garantizar el respeto del derecho a la integridad personal es por medio de su tipificación como delito en el COIP. Sin embargo, este no es el único mecanismo válido para ello, pues resulta necesario cambiar y modificar concepciones sociales y patrones culturales que lastran la efectividad del tipo penal.

No obstante, a pesar de la existencia de una regulación penal que analiza la relación que existe entre el derecho a la integridad personal y la violencia psicológica, aún persisten, desde esta concepción jurídica, algunas deficiencias que también inciden en la efectividad del precepto y su propósito. Dentro de estas se encuentra que la concepción de violencia psicológica solo sucede desde su incidencia en el ámbito familiar, sin tener en cuenta por el carácter integral, institucional y social, así como la afectación que causa al resto de los sectores vulnerables.

El maltrato psicológico, por su parte, si bien es menos perceptible que el físico, dificulta el hecho de las posibilidades probatorias, aun y cuando puede alcanzar niveles de gravedad muy superiores propios de la violencia física, ocasionando daños que muchas veces son irreversibles, lo cual guarda estrecha relación con la forma en que esta se manifiesta.

Por último, la atención psicológica que debe dársele a las víctimas de violencia psicológica es crucial para garantizar la recuperación emocional, su empoderamiento y la disminución de los riesgos; y de esta tarea debe encargarse el Estado ecuatoriano, mediante la puesta en práctica de las políticas públicas, planes y proyectos de orden social e institucional destinados a tal efecto.

\section{Referencias}

Afanador C., M. I. (2002). El derecho a la integridad personal. Elementos para su análisis. Reflexión Política, 4(8), pp. 92-104.

Albertín Carbó, P., \& Madurga, J. C. (2009). Algunas propuestas psicosociales para abordar el tratamiento de la violencia hacia las mujeres en los contextos jurídicopenales. Anuario de psicología jurídica (19), pp. 111-123.

Alexy, R. (1993). Teoría de los derechos fundamentales.(E. Garzón Valdés, Trad.) Madrid: Centro de Estudios Constitucionales.

Anello, C. S. (2012). Artículo 5. El derecho a la integridad física, psíquica y moral. En E. M. Alonso Regueira, Nro. 1 (Ed.), Convención Americana de Derechos Humanos y su proyección en el derecho argentino. Buenos Aires: La Ley. 
Antón García, L. (2014). Teorías criminológicas sobre la violencia contra la mujer en la pareja. Anales de la Cátedra Francisco Suárez(48), pp. 49-79.

Asensi, S. J. (1996). Constitucionalismo y derecho constitucional: materiales para una introducción. Valencia: Tirant lo Blanch.

Bueno Bueno, A. (1997). El maltrato psicológico/emocional como expresión de violencia hacia la infancia. Alternativas: Cuadernos de Trabajo Social(5), pp. 83-96.

Cáceres Carrasco, J. (2004). Violencia física, psicológica y sexual en el ámbito de la pareja: papel del contexto. Clínica y Salud, 15(1), pp. 33-54.

Camacho Z, G. (2014). La violencia de género contra las mujeres en el Ecuador: análisis de los resultados de la Encuesta Nacional sobre Relaciones Familiares y Violencia de Género contra las Mujeres. Quito, Ecuador: Consejo Nacional para la Igualdad de Género.

Canosa Usera, R. (2006). El derecho a la integridad personal. Madrid: Editorial Lex Nova.

Cabanellas de Torre, G. (1993). Diccionario jurídico elemental, nueva edición actualizada, corregida y aumentada. Buenos Aires: Editorial Heliasta.

El Universo. (23 de noviembre de 2015). Más de 16000 casos de violencia psicológica. El Universo. Obtenido de http://www.eluniverso.com/2015/11/23/video/5259432/ ecuador-hay-mas-16-mil-casos-violencia-psicologica.

Fernández Torres, M. J. (2013). El delito de tortura y su relación con otros atentados contra la integridad moral. (Universidad de Murcia, Tesis doctoral). Obtenido de htps://digitum.um.es/xmlui/bitstream/10201/37809/1

Fernández, V. (2008). Los nuevos aceleradores de la violencia remodernizada. En A. G. (Coord.), Nuevos escenarios de violencia. Reflexiones (págs. 17-47). Madrid: Universidad Pontificia Comillas.

Ferrajoli, L. (2004). Derechos y garantías. La ley del más débil. Traducción (4 ed.). (I. A. A., Trad.) Madrid: Trotta.

Galiano Maritan, G. (2016). El derecho a la vida como derecho fundamental en el marco constitucional ecuatoriano. Especial referencia al aborto, la eutanasia y la pena de muerte. Revista Jurídica Piélagus, julio-diciembre, 15(1), pp. 71-85.

Galiano Maritan, G. (2018). Análisis constitucional de los derechos personalísimos y su relación con los derechos del buen vivir en la Constitución de Ecuador. Revista de Derecho Privado, 34, pp. 123-156.

Galindo, J. A. (23 de 2009). Contenido del derecho a la integridad personal. Revista Derecho del Estado, Nro. 23, pp. 89-129.

García Calderón, J. (2000). Concepto de maltrato y violencia psíquica. Estudios sobre violencia familiar y agresiones sexuales vol II, pp. 203-212.

García-Baamonde Sánchez, M. E., Blázquez Alonso, M., \& Moreno Manso, J. (2012). El género como construcción sociocultural discriminatoria y violencia psicológica. En I. Vázquez Bermúdez, Investigación y género, inseparables en el presente y en el futuro (pp. 627-643). Sevilla: Universidad de Sevilla.

García-Toledano, F. (2018). Sobre la prevención de la violencia psicológica en el trabajo. Observatorio de Recursos Humanos y Relaciones Laborales (132), pp. 68-70.

Goyas Céspedes, L. S. (2018). Violencia contra la mujer y regulación jurídica del femenicidio en el Ecuador." Revista de Investigación en Derecho, Criminología y Consultoría Jurídica, 12 (23), pp. 129-150.

Guevara, J. (2007). La violencia de género: aspectos penales y procesales. Sevilla: Universidad de Sevilla. 
JBS. (1 de junio de 2016). Estadísticas evidencian problemática de violencia. El Mercurio. Guarderas, P. (2014). La violencia de género en la intervención psicosocial en Quito. Tejiendo narrativas para construir nuevos sentidos. . Athenea Digital, 3(14), pp. 79103. doi:http://dx.doi.org/10.5565/rev/athenea.1269.

Guastini, R. (2001). Estudios de teoría constitucional. México: Instituto de Investigaciones Jurídicas, Universidad Autónoma de México.

Gutiérrez Romero, F. M. (2013). El maltrato psicológico: presupuestos para su acreditación. Interiuris. Obtenido de El maltrato psicológico: presupuestos para su acreditación:: www.interiuris.org/archivos/2_EL_MALTRATO_PSICOLOGICO_PRE.pdf

Huertas Díaz, O., Barona Betancourt, R., Mora, J., Doncel Luna, L., Martínez , J., \& Sanabria, J. (2007); Barona Betancourt, R., Mora J. D., Doncel Luna, L., Martínez, J. M., Sanabria, J. A., La vulneración del Derecho a la integridad personal: el peor flagelo que puede sufrir un ser humano. Elementos de Juicio. Revista de Temas Constitucionales (6-7), 155-186.

Instituto Nacional de Estadística y Censos. (2011). Encuesta de Victimización y Percepción de Inseguridad realizada en el 2011. Obtenido de http://www.ecuadorencifras.gob. ec/documentos/web-inec/Victimizacion/Presentacion_principales_resultados.pdf

Joaquín Rodríguez, J. (2016). Intervención psicológica en violencia de género. En A. y. Gallardo Rodríguez, Desigualdad y violencia de género en un contexto de crisis generalizada, pp.1- 77.

JBS. (1 de junio de 2016). Estadísticas evidencian problemática de violencia. El Mercurio. Laurenzo Copello, P. (2005). El modelo de protección reforzada de la mujer frente a la violencia de género: valoración político-criminal. Revista Electrónica de Ciencia Penal y Criminología, Nro 2, pp.91-116.

Mendoza Calderón, S. (2004). Hacia un derecho penal sin fundamentación material del injusto: la introducción del nuevo Artículo 153 del Código Penal. En y. M. Miguel Ángel Boldova Pasamar, La reforma penal en torno a la violencia doméstica y de género (págs. 121-166). Barcelona: Atelier.

Mora Mojena, A. (2019). Capacitación para tratar la violencia intrafamiliar: una necesidad para los pedagogos. Hologramática, 3(31), pp. 56-79.

Olaizola Nogales, I. (2010). Violencia de género: elementos de los tipos penales con mayor dificultad probatoria. Estudios Penales y Criminológicos, XXX, pp. 269-316.

Organización de Estados Americanos. (2009). Informe sobre seguridad ciudadana y derechos humanos. Washington DC: Comisión Interamericana de Derechos Humanos.

Organización Mundial de la Salud. (2002). Resumen Informe mundial sobre la violencia y la salud.Washington, D.C.: Organización Mundial de la Salud.

Perela Larrosa, M. (2010). Violencia de género: violencia psicológica. Foto, Nueva Época(11-12):pp. 353-376).

Pérez Contreras, M. M. (1999). Violencia contra menores; un acercamiento al problema en México.Boletín Mexicano de Derecho Comparado, Nueva Serie, XXXII (96), n.p. Recuperado de: <https://revistas .juridicas .unam .mx/index .php/derecho-comparado/article/view/3614.

Peris Remón, P. y. (2019). La atención psicológica especializada en violencia de género. ReCRIM: Revista de l'Institut Universitari d'Investigació en Criminologia i Ciències Penals de la UV,(21), pp. 1-75.

Pérez, R. J. (1995). Curso de derecho constitucional. Madrid: M. Pons, Ediciones Jurídicas. 
Rodríguez Peregrina, J. (2015). Reflexiones político-criminales sobre la legislación penal en materia de violencia de género. Aequalitas: Revista Jurídica de Igualdad de Oportunidades entre Mujeres y Hombres(37), pp. 22-35.

Ramón Ribas, E. (2013). Los delitos de violencia de género según la jurisprudencia actual. Estudios Penales y Criminológico, XXXIII, pp. 401-464.

Real Academia de la Lengua Española. (2014). Diccionario de la Lengua Española. Obtenido de http://dle.rae.es.

Russo, E. A. (2001). Derechos humanos y garantías. El derecho al mañana. Buenos Aires: Editorial Universitaria de Buenos Aires.

Sar Suárez, O. (2008). Derecho a la integridad personal en el Perú. Aspectos constitutivos y limitaciones. El caso de las personas privadas de libertad. Cuestiones Constitucionales (19), pp. 211-236.

Sempere Faus, S. (2019). La atención psicológica especializada en violencia de género. En P. y. Peris Ramón, La victimización de las víctimas indirectas de la violencia de género: Los menores de edad (21 ed., págs. 1-75). Valencia: Editorial Universitat de València.

Soberanes Fernández, J. (2008). Retos y perspectivas actuales en materia de derechos humanos. Boletín Mexicano de Derecho Comparado (Número Conmemorativo). Sexagésimo aniversario, pp. 1193-1224.

Torrico Linares, M. E. (2011). La violencia psicológica, verbal y física. En U. d. Huelva (Ed.), Violencia escolar y de género: conceptualización y retos educativos (págs. 2142). Huelva: Universidad de Huelva.

Vilariño, T. L. (2011). La violencia psicológica, verbal y física. En A. D. lit.), Violencia escolar y de género: conceptualización y retos educativos (págs. 93-104). España: Universidad de Huelva.

Vivanco Martínez, A. (2011). Derecho y Violencia. Revista Chilena de Derecho, 38 (2), pp. 215 y 216.

Zurita Rivera, U. (2011). Los desafíos del derecho a la educación en México a propósito de la participación social y la violencia escolar. Revista Mexicana de Investigación Educativa, 16(48), pp.131-158.

\section{Tratados y leyes}

Asamblea General de las Naciones Unidas.(1948). Declaración Universal de los Derechos Humanos. Resolución 217 A (III), adoptada el 10 de diciembre de 1948 en París, Francia. Recuperado de: https://www.un.org/es/universal-declaration-humanrights/

.(1966). Pacto Internacional de Derechos Civiles y Políticos. Resolución 2200 A (XXI), de 16 de diciembre de 1966. Recuperado de: https://www.refworld.org.es/ docid/5c92b8584.html

(1984). Convención de las Naciones Unidas sobre la Tortura y Otros Tratos o Penas Crueles, Inhumanos o Degradantes. Resolución 39/46, de 10 de diciembre de 1984. Recuperado de: https://www.ohchr.org/sp/professionalinterest/pages/cat.aspx .(1989). Convención sobre los Derechos del Niño. Resolución 44/25, de 20 de noviembre de 1989. Recuperado de: https://www.ohchr.org/sp/professionalinterest/pages/crc. aspx 
.(2006). Convención sobre los Derechos de Personas con Discapacidad. 13 de diciembre de 2006. Recuperado de: https://www.un.org/esa/socdev/enable/ documents/tccconvs.pdf

Organización de Estados Americanos.(1948). Declaración Americana de los Derechos y Deberes del Hombre. Aprobada en la Novena Conferencia Internacional. Recuperado

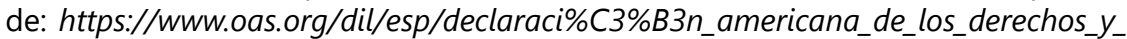
deberes_del_hombre_1948.pdf

(1969). Convención Americana sobre Derechos Humanos suscrita en la conferencia especializada Interamericana sobre Derechos Humanos, San José, Costa Rica. Pacto de San José). Recuperado de: ww.tce.gob.ec/jml/bajar/CONVENCION AMERICANA SOBRE DERECHOS HUMANOS.pdf

.(1985). Convención Interamericana para Prevenir y Sancionar la Tortura. Cartagena de Indias, Colombia. Recuperado de: http://www.ordenjuridico.gob.mx/TratInt/ Derechos\%20Humanos/D10.pdf

Constitución de la República del Ecuador. (20 de octubre de 2008). Incluye las reformas aprobadas en el Referéndum y Consulta Popular de 7 de mayo de 2011. Publicada en el Registro Oficial No. 449. Recuperado de: https://www.ambiente.gob.ec/wp-content/ uploads/downloads/2018/09/Constitucion-de-la-Republica-del-Ecuador.pdf

Constitución Española. (29 de diciembre,1978). Sancionada por el rey Juan Carlos I el 27 de diciembre y publicada en el Boletín Oficial del Estado de 29 de diciembre. Recuperado de: https://www.oas.org/dil/esp/Constitucion_Espa\%C3\%B1ola_27_ diciembre_1978.pdf

Asamblea Nacional República del Ecuador (1995, 11 de diciembre). Ley contra la violencia a la mujer y la familia. (1995). Ley 103/1995 de 11 de diciembre. Registro Oficial 839. Última modificación 10 de febrero de 2014. https://pdba.georgetown. edu/Security/citizensecurity/ecuador/leyes/leyviolenciamujer.pdf

Asamblea Nacional República del Ecuador. (2018, 5 de febrero). Ley Orgánica para prevenir y erradicar la violencia contra las mujeres. Ley 0 , Registro Oficial Suplemento 175. Quito, Ecuador. https://proteccionderechosquito.gob.ec/adjuntos/grupos/ mujeres/7_LEY_ORGANICA_INTEGRAL_PARA_PREVENIR_Y_ERRADICAR_LA_ VIOLENCIA_CONTRA_LAS_MUJERES.pdf

Asamblea Nacional República del Ecuador (2014, 10 de febrero). Código Orgánico Integral Penal. (2014). Serie Justicia y Derechos Humanos, Neoconstitucionalismo y Sociedad. Quito, Ecuador: Ministerio de Justicia, Derechos Humanos y Cultos Subsecretaría de Desarrollo Normativo. https://www.defensa.gob.ec/wp-content/ uploads/downloads/2018/03/COIP_feb2018.pdf

Asamblea Nacional República del Ecuador (2014, 7 de julio). Código de la Niñez y la Adolescencia, Ley 100, registro oficial 737 de 3 de enero de 2003, última modificación 7 de julio de 2014, Quito, Ecuador. https://www.igualdad.gob.ec/wpcontent/uploads/downloads/2017/11/codigo_ninezyadolescencia.pdf

\section{Jurisprudencia}

Corte Interamericana de Derecho Humanos. (1997, 17 de septiembre). Caso Loayza Tamayo vs. Perú. Sentencia de 17 de septiembre de 1997. https://www.corteidh. or.cr/docs/casos/articulos/seriec_33_esp.pdf 
Corte Interamericana de Derecho Humanos. (1999, 19 de noviembre). Caso Villagrán Morales y otros vs. Guatemala. Sentencia de 19 de noviembre de 1999. https:// www.corteidh.or.cr/docs/casos/articulos/Seriec_63_esp.pdf

Corte Interamericana de Derecho Humanos. (2006, 4 de julio). Caso Ximenes Lopes vs. Brasil. Sentencia de 4 de julio de 2006. https://www.corteidh.or.cr/docs/casos/ articulos/Seriec_149_esp.pdf

Corte Interamericana de Derecho Humanos. (2007, 11 de mayo). Caso Bueno Alves vs. Argentina. Sentencia de 11 de mayo de 2007. https://www.corteidh.or.cr/docs/ casos/articulos/seriec_164_esp.pdf

Corte Interamericana de Derecho Humanos. (2012, 30 de noviembre). Caso Masacre de Santo Domingo vs. Colombia. Sentencia de 30 de noviembre de 2012. https:// www.corteidh.or.cr/docs/casos/articulos/seriec_259_esp.pdf

Corte Constitucional de Colombia. (1994, 14 de marzo). Sentencia No. T-23/94, 14 de marzo de 1994.

Tribunal Supremo Español. Sala de lo Penal. (2000, 24 de junio). Sentencia número 927/2000 de fecha 24 de junio del 2000. https://supremo.vlex.es/vid/-51940712 